\title{
A Corpus-Based Study on the Use of Reporting
}

\section{Verbs in Applied Linguistics Articles}

\author{
Suwitchan Un-udom ${ }^{1} \&$ Nathaya Un-udom ${ }^{1}$ \\ ${ }^{1}$ English Department, the Faculty of Humanities and Social Sciences, Rajabhat Maha Sarakham University, \\ Thailand \\ Correspondence: Suwitchan Un-udom, English Department, the Faculty of Humanities and Social Sciences, \\ Rajabhat Maha Sarakham University, Thailand
}

Received: February 25, 2020

Accepted: March 29, 2020

Online Published: March 30, 2020

doi: 10.5539/elt.v13n4p162

URL: https://doi.org/10.5539/elt.v13n4p162

\begin{abstract}
Reporting verbs is one of the most important issues in writing academic paper because they are used to express the process and reliability of claims to support authors' writing. Therefore, the current study aimed at investigating (1) the most frequently used category of reporting verbs in applied linguistic articles and (2) how the category used in the citation process is used. 52 articles from three applied linguistic journals were analyzed using Antconc software's concordance function. This study focused on reporting verbs used in the literature review section since it consists of more reporting verbs than other sections in articles. The reporting verbs in the articles were analyzed into a concordance line and then were classified into Hyland's Framework of reporting verbs (2002). The results of the study showed that the uses of reporting verbs were classified into research acts, which was the most frequent use of reporting verbs, discourse acts, and cognition acts respectively. The study also presented the frequently used of reporting verbs in different subcategories of the research, discourse, and cognition acts. Additionally, reporting verbs were examined to investigate the verb forms and voices used in applied linguistic articles. The use of reporting verbs according to Hyland's (2002) framework, verb forms, and voices are also discussed.
\end{abstract}

Keywords: corpus-based method, applied linguistic articles, reporting verbs, concordance line

\section{Introduction}

Scholars in the academic setting are required to use specific linguistic patterns to complete a piece of publication. Especially in writing a manuscript that is expected to be reviewed by publication, writers would be forced to deliberate their language more carefully in order to pass the evaluation (Silva, 2007). Moreover, studies have suggested that academic researchers employ specific uses of language at all levels including words (Coxhead, 2000), sentence structures (Alvin, 2014), and rhetorical moves (Swale, 2004). Therefore, it is not an easy task to complete an academic paper that is acceptable for journal publication.

One of the issues in academic writing is the use of language conveying reporting meaning in the citation of other publications. It is noted that the citation process and reliability of claims could be affected by the use of particular reporting verbs (Hyland, 2005). According to Charles (2006), the correct use of reporting verbs brings about the expression of ideas the writers want to convey through the quotes or citations. Therefore, it is important for learners of academic writing to master the use of reporting verbs in the citation (Clugton, 2008).

According to Soler-Monreal and Salom (2011), in all parts of sections in an academic writing setting, a literature review is a part that could consist of most of the citations and reporting verbs. This part of the academic article aims to reviews the principle of the topic and the previous studies related to the topic. Therefore, the use of reporting verbs is required to express such an idea of language use. Differently, in the other parts of academic publication, reporting verbs are requested less as the authors could employ their own ideas or rely on the results of the study.

Even though it is quite obvious where to use the reporting verbs in the article, the question of how the verbs are used could still be in question. Because many reporting verbs could be used in the citation process, the questions in both research and pedagogy are raised whether reporting verbs are normally used and how they could be used. Research studies have been conducted to answer the questions, for example, in the ESL MA thesis (Manan \& 
Noor, 2014), Chemistry (Gooden, 2001,) and Applied Linguistic articles (Jafarigohar \& Mohammadkhani, 2015). Therefore, it might contribute to the instruction of academic writing if the uses of reporting verbs are investigated in depth.

The rise of technology has become influential in language studies. One of the influential technological-based methods used widely to study linguistic phenomena is corpus linguistics. According to Biber et' al (1998), a corpus-based study aims at applying technology to examine patterns of language uses by studying a large collection of naturally existing texts in the real uses of languages. In this case, corpus linguistic could be used as a method to systemically provide evidence of reporting verbs uses in a specific context.

\subsection{Objective of the Study}

1.1.1 To investigate the most frequently used category of reporting verbs in applied linguistic articles

1.1.2 To investigate how the categories of reporting verbs used in the citation process of applied linguistic articles are used

\subsection{Research Questions}

1.2.1 What is the most frequently used category of reporting verbs in applied linguistic articles?

1.2.2 How is the category used in the citation process of applied linguistic articles?

\section{Theoretical Framework}

In order to develop an instruction tool for specific courses of English, it is significant to use systematic evidence to support the instrument. One of the methods proved to be effective is creating corpora to report the actual uses of language patterns in such the context (McEnery \& Xiao, 2011). To explain, the method could lead to the real use of language patterns such as specific vocabulary, rhetorical moves, and the uses of linguistic structures and increase the reliability of instructional tools evidenced by results of corpus-based studies (Widdowson, 2004).

\subsection{Reporting Verbs}

Teaching academic writing is one of the most difficult duties of teachers (Bailey, 2003). Learners of academic writing have to deal with several issues including grammar and mechanics, organization and rhetorical moves, and specific requirements of language. One of the outstanding characteristics of academic writing is citations. Different from other kinds of writing, academic writers need to use words to create reliability and credibility to the text (Hyland, 2000). As mentioned earlier, the importance of citation and reporting verbs in academic writing leads to the need to include issues to the instruction. The study of reporting verbs in academic publications using the corpus-based method could empower the instruction tools to teach academic writing.

Researchers have presented criteria to identify and classify reporting verbs in academic settings (e.g., Hyland, 1999; Hyland 2002; Thomson \& Ye 1991). One of the insightful principles was presented by Hyland (2002) who categorized reporting verbs into three main types according to the functional uses of the verbs namely research act, cognitive act, and discourse acts. In detail, the research act reporting verbs can be divided into procedure and finding. The procedure verbs are used to present methods used in the cited work such as analyze, calculate, assay, explore, plot, recover. In the finding act, the authors employ factive verbs (demonstrate, establish, show, solve, confirm) to accept the result of others, counter-factive verbs (fail, misunderstand, ignore, overlook) to show unacceptance of the result, and non-factive verbs (find, identify, observe, obtain) to show neutral comment on the result.

In the second category, a writer could use reporting verbs to illustrate the authors' attitudes towards the reported statement. The four sub-categories are presented including positive attitude (agree, concur, hold, know, think, or understand) used when authors accept the information as true or correct, tentative view (believe, doubt, speculate, suppose, suspect), critique (disagree, dispute, no think), and neutral stance (picture, conceive, anticipate, reflect).

In the last category, discourse act, the reporting verbs are used to convey an evaluation of the citation. The author could either take responsibility as an interpreter who conveys uncertainty or assurance of the correctness and attributing a qualification to the author. In detail, the verbs that express the authors' view directly are categorized into doubt and assurance categories. The former can be further divided into tentative verbs (postulate, hypothesize, indicate, intimate, suggest) and critical verbs (evade, exaggerate, not account, not make a point) while the latter is divided into non-factive verb such as state, describe, discuss, report, answer, define, summarize and factive verb such as argue, affirm, explain, note, point out, and claim. In the last sub-category, the counter category, the verbs are used to state the objects of the cited author. The examples of this subcategory are "deny", "critique", "challenge", "attack", "question", "warn", and "rule out". The summary of Hyland's (2002) framework could be seen in the figure below. 


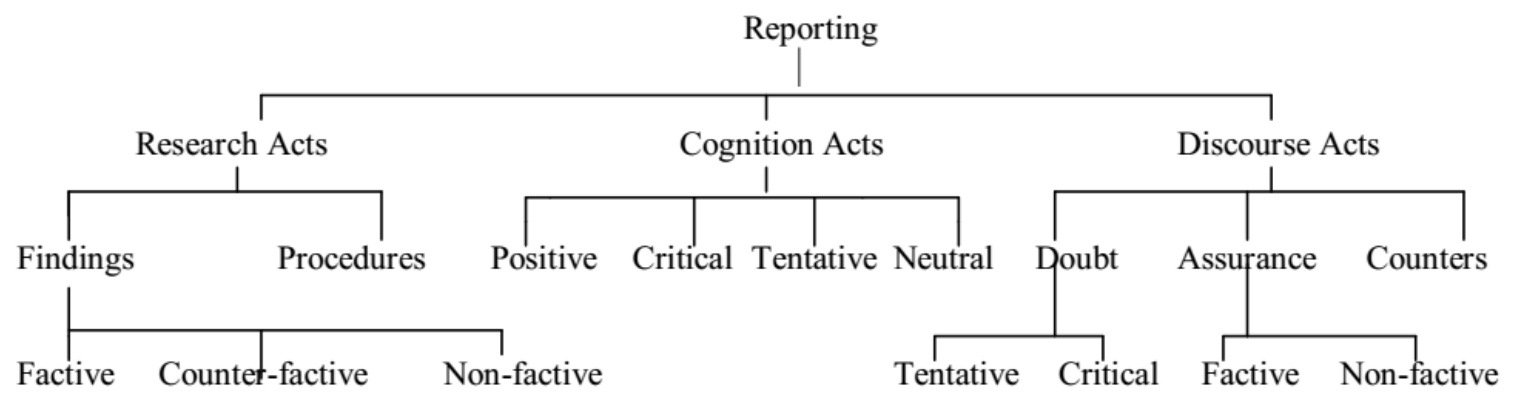

Figure 1. Hyland's Framework of reporting verbs (2002, P. 122)

\subsection{Previous Studies}

Due to the importance of the use of reporting verbs in academic writing and the influence of the corpus-based method in language study, there have been attempts to study the issue by using the corpus base method. To explain, corpus-based studies have been conducted to investigate the reporting verbs in both non-linguistics and linguistic fields. The studies show the different result which could be beneficial for pedagogical implication.

The studies of non-linguistic context

The area of studies is considered one of the important factors influencing the use of language in writing reports (Shashok, 2008). Therefore, there are attempts to study the use of reporting verbs in several areas apart from linguistics such as medicine (Jirapanakorn, 2012), chemistry (Gooden, 2001), and sciences (Rodiguez, 2007). The studies looked at different angles of reporting verbs in the specific area. For example, Jirapanakorn (2012) study the difference between Thai and International researchers in using reporting verbs in article publications. The 18,284 token corpora were compiled from a comparable amount of both Thai (8609 tokens) and international (9675 tokens). The result of the studies show that Thai and International researchers share the most frequently used reporting verbs (show); however, there are differences in the other place of order in the use of the verbs.

The studies of linguistic context

The studies of reporting verbs in academic writing of linguistic field also gain interest as corpus-based studies have been conducted to investigate the use of the verbs in the field related to language (e.g., Charles, 2006; Loan \& Pramoolsook, 2015; Jafarigohar \& Mohammadkhani, 2015; Manan \& Noor, 2014). The studies investigated a wild range of reporting verbs uses. Loan and Pramoolsook (2015) and Manan and Noor (2014) looked at the use of reporting verbs in the thesis while Charles (2006) studied deeper in the phase level. In detail, the study of reporting verb use in academic journals where papers are proved more intensively by committees and editorial boards could be seen in the study of Jafarigohar and Mohammadkhani (2015). The study was conducted to compare the use of reporting verbs of native and non-native authors publishing their works in the three journals in applied linguistics area. The corpora were compiled from 64 articles of approximately 200,000 tokens. The result of the study showed that there are differences in the use of reporting verbs between native and non-native authors in direct quotes. However, the study bares limitations in methodology in terms of the criteria of choosing journals and the procedure of finding citations. The authors failed to validate the reasons why the three journals were chosen and the manual search of the citation might lead to the unreliability of the data.

The requirement in academic publication seems to be more specific than in other genres of writing. Therefore, the instruction of academic writing becomes one of the crucial problems in the EFL context. Reporting verbs are important in the citation process which is one of the major characteristics of academic writing. However, since there are many reporting verbs existed, how to appropriately use the verb is still the question in EFL instruction. Studying the real use of language in a natural setting is could lead to a reliable resource for instructional tools. The corpus-based method becomes influential in the study of language patterns. As a result, studies attempt to apply corpus linguistics as a method to investigate the pattern of reporting verbs in academic writing in applied linguistics. However, only a few studies investigate the use of verbs in academic publications. Moreover, the previous studies, as mentioned earlier, still left gaps in the methodology. The current study attempted to apply the more specific method to systemically select the journal of publication and search the lexical items to answers the research questions which were 


\section{Method}

\subsection{Research Design}

The corpora were compiled from 84 articles in three journals in applied linguistic area. The journals were selected by the impact factors. According to TESOL (2015), there are 52 journals recommended in applied linguistic areas published in the year 2015. The journals found to have the impact factor above 1.5 level were selected. The journals that met criteria were English for Specific Purpose, Journal of second language writing, and Language Learning. The corpora were compiled only from the literature review part as it proved to have the most frequent uses of reporting verbs (Soler-Monreal \& Salom (2011). The corpora consist of 201,785 tokens, and the detail of the corpora could be found in Table 1 below.

Table 1. The corpora from the three Applied Linguistic Journals

\begin{tabular}{cccc}
\hline Journal & Articles & Tokens & Impact factor \\
\hline English for Specific Purpose & 31 & 50,433 & 1.53 \\
Journal of Second Language Writing & 22 & 58,372 & 2.49 \\
Language Learning & 31 & 92,980 & 1.79 \\
Total & 84 & 201,785 & - \\
\hline
\end{tabular}

\subsection{Data Collection and Procedures}

The purpose of the study was to investigate the use of reporting verbs used in the citation in applied linguistic academic articles. According to Hyland (1999), the citation is defined as the reference of other sources to a statement. Moreover, Shim (2005) defined citation as an attempt to contribute to the credibility of the work by referring to the authors' works. In addition, Swale (1990) indicated that the citation could be both occur with the name of the author (integral citation) and without the name of the author (non-integral citation). Therefore, it could be synthesized that reporting verbs could be defined as the verbs that are used in the citation process which is the attempt to contribute credibility of the work by referring to the other works both with name and without the name of the authors. The current study employed Hyland's (2002) principle in categorizing the reporting verbs. The target words were 138 reporting verbs in Loan and Pramoolsook (2015) who employed a similar principle in categorizing reporting verbs. The lexical items were analyzed by the following criteria.

1) The verbs must express the citation of other works with both integral and non-integral pattern defined by Swale (1990).

2) All frequencies of word forms in a lemma were put together.

\subsection{Data Analysis}

The complied corpora were analyzed by the Antconc software's concordance function. 138 target words were searched with all possible lemmas, and the concordance lines of each word were analyzed. The occurred patterns that met the criteria were counted and were used to answer the first research question. The most used category was later analyzed to investigate the patterns used in the citation process to answer the second research question.

\section{Results and Discussion}

\subsection{What is the Most Frequently used Category of Reporting Verbs in Applied Linguistic Articles?}

Table 2 below shows the reporting verbs used in the literature review section in the three applied linguistic journals. According to Hyland's (2002) framework, the reporting verbs categorized in the research act (58.4\%) were the most found in the articles. Each subcategory of research acts consists of finding and procedure in which their coverage of finding (30.02\%) was moderately higher than the procedure $(28.38 \%)$. Additionally, as categorized in finding, there were no reporting verbs used as counter-factive $(0 \%)$ while the different frequent uses of reporting verbs of non-factive $(22.59 \%)$ were higher than factive $(7.43 \%)$. The second rank of the use of reporting verbs was discourse acts $(35.12 \%)$. Assurance $(28.28 \%)$, a subcategory of discourse acts, was the highest among doubt $(6.84 \%)$ and counters $(0 \%)$. As assurance also has its subcategories, it was found that factive $(15.01 \%)$ is moderately higher than non-factive (13.27\%). Another subcategory of discourse acts was doubt which consisted of tentative (6.49\%) and critical ( $0.35 \%)$. Another type of reporting verbs is cognition acts. From this study, the cognition act was the least type of reporting verbs. Since this type consists of four categories, the frequent use of reporting verbs in cognition acts was tentative $(4.75 \%)$, neutral $(1.14 \%)$, positive $(0.59 \%)$, and critical $(0 \%)$ respectively. 
Table 2. Classification of RVs according to Hyland's framework (2002)

\begin{tabular}{|c|c|c|}
\hline \multirow{4}{*}{$\begin{array}{l}\text { Research acts } \\
1,179(58.4 \%)\end{array}$} & \multirow{4}{*}{$\begin{array}{l}\text { Finding } 606(30.02 \%) \\
\text { Procedure } 573(28.38 \%)\end{array}$} & Factive $150(7.43 \%)$ \\
\hline & & Counter-factive $0(0 \%)$ \\
\hline & & Non-factive $456(22.59 \%)$ \\
\hline & & \\
\hline \multirow{4}{*}{$\begin{array}{l}\text { Cognition acts } \\
131(6.48 \%)\end{array}$} & Positive $12(0.59 \%)$ & \\
\hline & Critical $0(0 \%)$ & \\
\hline & Tentative $96(4.75 \%)$ & \\
\hline & Neutral $23(1.14 \%)$ & \\
\hline \multirow{5}{*}{$\begin{array}{l}\text { Discourse acts } \\
709(35.12 \%)\end{array}$} & \multirow{2}{*}{ Doubt 138 (6.84\%) } & Tentative 131 (6.49\%) \\
\hline & & Critical $7(0.35 \%)$ \\
\hline & \multirow{2}{*}{ Assurance $571(28.28 \%)$} & Factive $303(15.01 \%)$ \\
\hline & & Non-factive $268(13.27 \%)$ \\
\hline & Counters $0(0 \%)$ & \\
\hline
\end{tabular}

The result of the study was not related to Hyland (2002) and Loan and Pramoolsuk (2015). In the studies, the reporting verbs in the discourse act were the majority of the category. In detail, in Hyland's (2002) study, 57\% of reporting verbs were categorized in discourse act while $62 \%$ were found in the study of Loan and Pramoolsuk (2012). However, the result of the current study pointed out that the majority (58.4\%) of the reporting verbs in the applied linguistic academic articles were in the research act category. In particular, three studies investigated different ankles of reporting verb use. In Hyland's and Loan and Pramoolsuk's studies, the principle of Hyland in categorizing reporting verbs was used to consider the acts of reporting verbs used in the publication. The coverage percentage of the verb of two studies was due to the number of existing reporting verbs according to the principle of Hyland (2002). In contrast, in the current study, the existing verbs were tested to identify how they are used in the writing academic articles, and the result of the study showed a superior number of the research act reporting verbs. It could be discussed that the number of existence could not guarantee the frequency in the real use of the verbs. Even though there were more verbs in the discourse acts, the most frequently used verbs were the research acts category.

\subsection{How is the Category used in the Citation Process of Applied Linguistic Articles?}

After classifying the reporting verbs into Hyland's (2002) framework, they were analyzed to examine how they were used in the issues of verb forms and voices. As shown in Table 3, the highest form used in the literature review section in applied linguistic articles was a past form (50.21\%) while the least was present participle (2.21\%). Additionally, past participle (24.17\%) employed in writing was considered as the second rank while root $(15.35 \%)$ and third-person singular $(8.06 \%)$ forms respectively were less employed than past participles. Moreover, as classifying into voices, reporting verbs were more used in the active voice $(85.16 \%)$ than passive voice $(14.84 \%)$. Therefore, the result of this study revealed the use of reporting verbs in different dimensions, classified by Hyland's (2002) framework, and also their use in both verb forms and voices.

Table 3. Verb forms of reporting verbs

\begin{tabular}{ccc}
\hline Verb form & Frequency & Coverage \\
\hline Root & 181 & 15.35 \\
Third person singular & 95 & 8.06 \\
Past form & 592 & 50.21 \\
Past participle & 285 & 24.17 \\
Present participle & 26 & 2.21 \\
& 1,179 & 100.00 \\
\hline
\end{tabular}


Table 4. Voices of reporting verbs

\begin{tabular}{cc}
\hline \multicolumn{2}{c}{ Voice } \\
\hline Active & Passive \\
1,004 & 175 \\
$85.16 \%$ & $14.84 \%$ \\
\hline
\end{tabular}

The superior existence of past form of verbs in applied linguistic articles led to the discussing issue in the verb form existence. It could be noticed from the result of the study that even though past participle form of verbs could be used to form both perfect tenses and passive voice sentences, the past form of verbs was still used in the most frequent amount. This could be explained by the characteristic of the literature review given by Bitchener (2009) that literature review should focus on what people in the area have done. Therefore, the use of past simple which require past form of verbs could commonly found in the section of the academic articles. In detail, patterns of past and past participle form could be seen in the result of the study. The uses of past form of verbs could be spotted after the cited researchers to inform the action of the scholars. On the other hand, when it came to a group of researchers doing actions to the area, the use of past participle could be seen. The example of the linguistic patterns could be seen in the figure below.

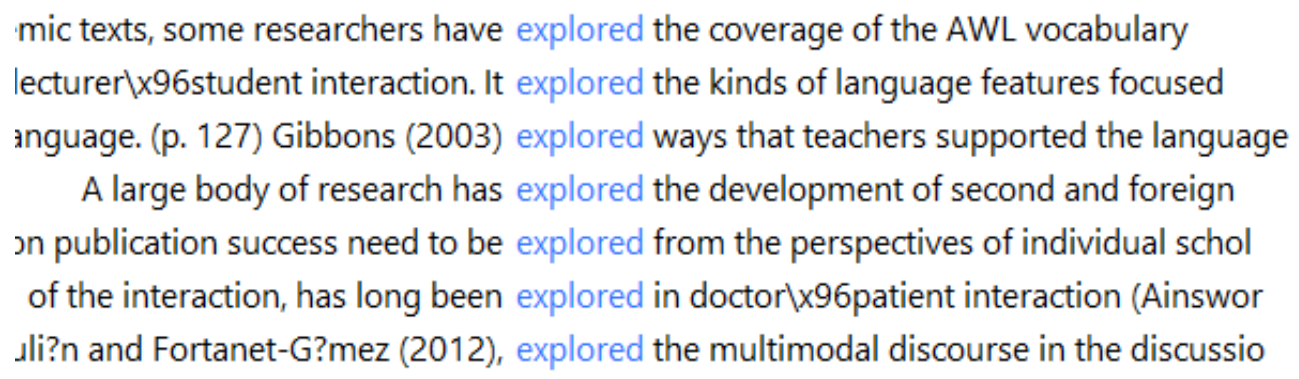

Figure 2. The use of past and past participle verb forms

Moreover, in the issues of voices of speech, it could be seen in the result of the study that reporting verbs were used in active voice than passive voice statements. The result of the study came along with the study of Thomson (2001), and Loan and Pramoolsuk (2015). Moreover, the greater existence of active voices could also found in the academic publication in several areas such as social sciences (Hyland, 2002) and agriculture (Thomson, 2002). This could be explained by the structure of the sentence. In passive voice, the main verb form used to form the structure is past participle while all forms of verbs could be used to form active sentences. Therefore, the greater occurrence of active sentences could be found in the study.

\section{Conclusion}

The results of the study could be drawn to the conclusion that 1) the research acts were the most frequently used reporting verb category in applied linguistic academic articles, and 2) the verbs were mainly used in the past simple form and to form active voice sentences. The results of the study could be implicated in both academic and pedagogical areas. In detail, the study could be used to be evidence to support the patterns in composing literature review part of an academic article in the issue of reporting verb use. Moreover, it could be seen that both thesis and academic publications used the similar pattern of reporting verbs. Pedagogically, instructors of academic writing could use the results of the study to design their materials related to the citation and the use of reporting verbs.

Even though the methodology could lead to answers to the research questions, some limitations were acknowledged. First, the corpora size could be too small to be representative of all articles in applied linguistic articles. Moreover, the articles selected in the current study were only from three journals; therefore, it could not control the balance of the corpora. In addition, the reporting verbs investigated in the study were chosen from only the result of one study. It might not cover all the reporting verbs existing in English. Further studies could be conducted with more coverage and balance corpora. More reporting verbs could be investigated to answer the question that the current study could not find in order to contribute sets of knowledge to the area of corpus-based and vocabulary study. 


\section{References}

Alvin, L. P. (2014). The passive voice in scientific writing: The current norm in science journals. Journal of Science Communication, 13(1), 1-16. https://doi.org/10.22323/2.13010203

Bailey, S. (2003). Academic writing a handbook for international students. New York: Routledge. https://doi.org/10.4324/9780203464120

Biber, D., Conrad, S. \& Reppen, R. (1998). Corpus Linguistics: Investigating Language Structure and Use. Cambridge University Press. https://doi.org/10.1017/CBO9780511804489

Bitchener, J. (2009). Writing an applied linguistics thesis or dissertation: A guide to presenting empirical research. Palgrave Macmillan. https://doi.org/10.1007/978-1-137-04337-5

Charles, M. (2006). Phraseological patterns in reporting clauses used in citation: A corpus-based study of theses in two disciplines. English for Specific Purposes, 25, 310-331. https://doi.org/10.1016/j.esp.2005.05.003

Clugston, M. F. (2008). An analysis of citation forms in health science journals. Journal of Academic Language and Learning, 2, 11-22.

Coxhead, A. (2000). A new academic word list. TESOL Quarterly, 34(2), 213-238. https://doi.org/10.2307/3587951

Golden, A. M. (2001). Citation analysis of chemistry doctoral dissertation: An Ohio State University case study. Issues in Science \& Technology Librarianship, 32(32), 1-16.

Hyland, K. (1999). Academic attribution: Citation and the construction of disciplinary knowledge. Applied Linguistics, 20(3), 349-351. https://doi.org/10.1093/applin/20.3.341

Hyland, K. (2002). Directives: Argument and Engagement in Academic Writing. Applied Linguistics, 23(2), 215-239. https://doi.org/10.1093/applin/23.2.215

Hyland, K. (2000). Disciplinary discourses: Social interactions in academic writing. Harlow, UK: Longman.

Hyland, K. (2005). Stance and engagement: A model of interaction in academic discourse. Discourse Studies, 7, 172-192. https://doi.org/10.1177/1461445605050365

Jafarigohar, M. \& Mohammadkhani, A. (2015). Reporting Verbs in Applied Linguistics Research Articles by Native and Non-native Writers. Theory and Practice in Language Studies, 5(12), 2490-2496. https://doi.org/10.17507/tpls.0512.08

Jirapanakorn, N. (2012). How doctors report: A corpus-based contrastive analysis of reporting verbs in research article introductions published in international and Thai medical journals. The Bangkok Medical Journal, 4, 39-46. https://doi.org/10.31524/bkkmedj.2012.09.007

Loan, T. \& Pramoolsook, I. (2015). Reporting verbs in literature review chapters of TESOL master's theses. Journal of English for Specific Purposes at Tertiary Level, 3(2), 196-215.

Manan, N. A. \& Noor, M. N. (2014). Analysis of Reporting Verbs in Master's Theses. Procedia - Social and Behavioral Sciences, 134, 140-145. https://doi.org/10.1016/j.sbspro.2014.04.232

McEnery, T. \& Xiao, R. (2011). What corpora can offer in language teaching and learning? Handbook of research in second language teaching and learning, 2, 364-380.

Rodríguez, C. I. L. (2007). Understanding scientific communication through the extraction of the conceptual and rhetorical information codified by verbs. Terminology, 13(1), 6-84. https://doi.org/10.1075/term.13.1.04lop

Shashok, K. (2008). Content and communication: how can peer review provide helpful feedback about the writing? BMC Medical Research Methodology, 8(8), 3. https://doi.org/10.1186/1471-2288-8-3

Shim, E. (2005). Explicit writing instruction in higher education context: Genre analysis of research article introductions from the English Teaching and the TESOL Quarterly Journals. Unpublished doctoral dissertation, University of Minnesota.

Silvia, P. J. (2007). How to write a lot: A practical guide to productive academic writing (Vol. xii). Washington, DC, US: American Psychological Association.

Soler- Monreal, C. \& Gil- Salom, L. (2011). A cross-language study on citation practice in $\mathrm{PhD}$ theses. International Journal of English Studies, 11(2), 53-75. https://doi.org/10.6018/ijes/2011/2/149641

Swale, J. M. (1990). Genre analysis. Cambridge: Cambridge University Press. https://doi.org/10.1017/CBO9781139524827 
Swales, J. (2004). Research genres: Explorations and applications. Cambridge: Cambridge University Press.

TESOL Convention \& Exhibit (2015). How to Get Published in TESOL and Applied Linguistics Serials. Retrieved 2016, April 3 from https:/www.tesol.org/docs/default-source/ books/how-to-get-published-in-applied-linguistics-serials.pdf?sfvrsn=4

Thompson, G. \& Yiyun, Y. (1991). Evaluation in the reporting verbs used in academic papers. Applied linguistics, 12(4), 365-382. https://doi.org/10.1093/applin/12.4.365

Widdowson, H. G. (2004). Text, Context, Pretext. London: Blackwell. https://doi.org/10.1002/9780470758427

\section{Copyrights}

Copyright for this article is retained by the author(s), with first publication rights granted to the journal.

This is an open-access article distributed under the terms and conditions of the Creative Commons Attribution license (http://creativecommons.org/licenses/by/4.0/). 